\title{
Surveillance of suicidal behaviour by the Belgian Network of Sentinel General Practices: trends over two decades
}

\author{
Nicole Boffin ${ }^{*}$, Sarah Moreels, Viviane Van Casteren \\ From Methods in Epidemiology Symposium \\ Leuven, Belgium. 17 September 2015
}

\section{Objectives}

Drawing on new (2011-12) and previous (1993-5, 2000-1 and 2007-8) data on suicidal behaviour reported by the Belgian Network of Sentinel General Practices (SGP), we describe trends in the key characteristics of suicidal events. We also examine patient age-related trends in the on-site attendance of sentinel general practitioners (GPs) as first professional caregivers following suicidal behaviour and the accuracy of suicide incidence estimates. Outcome measures: Patient age and gender, suicide methods, whether the GP was the first caregiver on-site, whether the patient was new, and the outcome of the suicidal behaviour (fatal or not) were recorded on standard registration forms. The accuracy of suicide incidence estimates was tested against suicide mortality statistics.

\section{Results}

Over the four time periods, 1671 suicidal events were reported: 275 suicides, 1287 suicide attempts and 109 events of suicidal behaviour of unknown outcome. In 2011-12, sentinel GPs' on-site attendance following the suicidal behaviour of patients $<65$ years had continued to decrease (from $71 \%$ in $1993-5$ to $58 \%$ in $2000-1$, $39 \%$ in 2007-8 and $25 \%$ in 2011-12). In 2011-12, it had also decreased steeply in the population $=65$ years (from $70 \%$ in $1993-5,76 \%$ in $2000-1$ and $79 \%$ in $2007-8$ to $35 \%$ in 2011-12). No significant differences were found between the SGP-based suicide incidence estimates for 2011-2 and the available suicide mortality rates for people $<65$ years and $=65$ years

Scientific Institute of Public Health, Brussels, Belgium

\section{Conclusions}

GPs' on-site attendance as first professional caregivers following suicidal behaviour continues to decline, since 2011-2 also in the population $=65$ years. Unawareness of patients' suicidal behaviour endangers both care for surviving patients and the completeness of SGP surveillance data. Yet, the incidence of suicide for 2011-12 was estimated accurately by the SGP.

Published: 17 September 2015

doi:10.1186/2049-3258-73-S1-P40

Cite this article as: Boffin et al: Surveillance of suicidal behaviour by the Belgian Network of Sentinel General Practices: trends over two decades. Archives of Public Health 2015 73(Suppl 1):P40.
Submit your next manuscript to BioMed Central and take full advantage of:

- Convenient online submission

- Thorough peer review

- No space constraints or color figure charges

- Immediate publication on acceptance

- Inclusion in PubMed, CAS, Scopus and Google Scholar

- Research which is freely available for redistribution 